\title{
Discurso Político em Site de Rede Social: O Caso da Fanpage do Tribunal Superior Eleitoral ${ }^{1}$
}

\author{
Political Speech on Social Networking Site: The Fanpage Case of the \\ Superior Electoral Court
}

\section{Discurso político en el sitio de redes sociales: El caso Fanpage del Tribunal Superior Electoral}

\author{
Karen dos Santos Correia \\ Universidade da Amazônia - UNAMA - Brasil \\ ORCID: https://orcid.org/0000-0002-4150-0648 \\ Endereço currículo Plataforma Lattes: http://lattes.cnpq.br/9313626842801953 \\ E-mail: karenletrasrp@gmail.com \\ Analaura Corradi \\ Universidade da Amazônia - UNAMA - Brasil \\ ORCID: https://orcid.org/0000-0003-0432-1875 \\ Endereço currículo Plataforma Lattes: http://lattes.cnpq.br/1114323930575998 \\ E-mail: corradi7@gmail.com \\ Douglas Junio Fernandes Assumpção \\ Universidade da Amazônia - UNAMA - Brasil \\ ORCID: https://orcid.org/0000-0001-5048-6692 \\ Endereço currículo Plataforma Lattes: http://lattes.cnpq.br/5101210815023238 \\ E-mail: rp.douglas@hotmail.com
}

Resumo: O presente artigo objetiva analisar o conteúdo informativo de uma postagem publicada na fanpage do Tribunal Superior Eleitoral (TSE). A publicação analisada aborda sobre a divulgação de fake news nos sites de redes sociais e o papel do TSE diante das ocorrências de notícias falsas no processo eleitoral de 2018. Diante disso, para refletir sobre essas questões, tem-se a seguinte problemática: "Como o conteúdo informativo na fanpage do TSE contribuiu para reforçar os discursos políticos que permearam as eleições de 2018 no Brasil?’”. A abordagem metodológica utilizada é a Análise de Discurso Mediado pelo Computador (ADMC), proposta por Susan Herring (2004), para obter dados que comprovam a materialização e o reforço dos discursos políticos defendidos pelos eleitores brasileiros que interagem com a fanpage do TSE.

Palavras-Chave: Análise do Discurso. Facebook. Discurso Político. Eleições 2018. Tribunal Superior Eleitoral. 
Abstract: This article aims to analyze the informative content of a post published in the fanpage of the Superior Electoral Court (TSE). The analyzed publication deals with the dissemination of Fake News on social networks and the role of the TSE in the face of false news occurrences in the 2018 electoral process. Thus, to reflect on these issues, we have the following problem: contributed to reinforcing the political speeches that permeated the 2018 elections in Brazil? ". The methodological approach used is Computer-Mediated Discourse Analysis (ADMC), proposed by Susan Herring (2004), to obtain data that substantiate and reinforce the political discourses defended by Brazilian voters who interact with the TSE fanpage.

Keywords: Speech analysis. Facebook. Political speech. Elections 2018. Superior Electoral Court.

Resumen: Este artículo tiene como objetivo analizar el contenido informativo de una publicación publicada en la fanpage del Tribunal Superior Electoral (TSE). La publicación analizada trata sobre la difusión de Fake News en las redes sociales y el papel del TSE frente a las noticias falsas en el proceso electoral de 2018. Por lo tanto, para reflexionar sobre estos temas, tenemos el siguiente problema: ¿contribuyó a reforzar los discursos políticos que impregnaron las elecciones de 2018 en Brasil? ”. El enfoque metodológico utilizado es el Análisis del discurso mediado por computadora (ADMC), propuesto por Susan Herring (2004), para obtener datos que corroboren y refuercen los discursos políticos defendidos por los votantes brasileños que interactúan con la página de fans de TSE.

Palabras Clave: Análisis del discurso. Facebook. Discurso político. Elecciones 2018. Tribunal Superior Electoral.

\section{Introdução}

As novas tecnologias de informação trouxeram, para a sociedade, avanços significativos para que novas formas de se relacionar começassem a ser estabelecidas. As redes sociais virtuais são exemplos dessas mudanças que a cada instante se torna mais rápida, interativa, com novas estruturas, conexões e práticas sociais e discursivas.

Hoje, como um dos mais populares sites de redes sociais, o Facebook apresenta 127 milhões de usuários no Brasil, de acordo com a Empresa Brasil de Comunicação (EBC), são usuários que estão interagindo com outros usuários, com grupos e com fanpages, fazendo com que a produção e reprodução de textos e imagens aconteçam a todo instante. 
E esta rede social se tornou uma ferramenta de comunicação muito utilizada nas eleições de 2018 no Brasil por candidatos, eleitores, órgãos públicos, dentre outros, para divulgar informações de seu interesse, ocasionando com isso fluxos de interações e compartilhamentos de conteúdos a cerca de um determinado assunto eleitoral.

O crescimento do uso do Facebook, no Brasil nos últimos anos, trouxe novos contextos para os processos de comunicação e para os discursos. Esses novos contextos permitem também que novas e antigas práticas sociais emirjam e se popularizem nas redes sociais online. (RECUERO, 2013, p. 240).

Diante disso, este trabalho busca compreender sobre essa nova prática social permitida pelo Facebook em reforçar discursos materializados pela linguagem midiática que funciona como uma importante instituição social que ajuda a produzir as vontades de verdade de seus interlocutores, colocando em circulação efeitos de sentido desses discursos reproduzidos. (GREGOLIN, 2007).

Por isso, para compreender como os discursos são reforçados a partir de uma postagem no Facebook, implica-se na seguinte problemática: "Como o conteúdo informativo na fanpage do Tribunal Superior Eleitoral (TSE) contribuiu para reforçar os discursos políticos das eleições de 2018 no Brasil?". O objetivo, com isso, é analisar o conteúdo informativo da postagem publicada no dia 31 de outubro de 2018 na fanpage do TSE, que trata sobre o cuidado ao divulgar fake news nas redes sociais.

A fanpage do TSE foi escolhida como estudo de caso porque é uma página do Facebook que corresponde ao órgão máximo da Justiça Eleitoral no país. A publicação do dia 31 de outubro de 2018 foi selecionada por ter sido a primeira postagem publicada pelo TSE que trata sobre fake news logo após as eleições que foram permeadas por escândalos e acusações envolvendo os presidenciáveis de 2018.

Assim, a postagem selecionada faz menção às fake news, notícias essas que foram responsáveis por diversos discursos reforçados, reproduzidos, materializados e legitimados durante as eleições de 2018.

O termo fake News é utilizado pelo TSE no seu site de rede social Facebook para designar "notícias falsas", mas podemos apontar, também, nesta discussão o termo que está sendo amplamente utilizado para designar as notícias falsas: desinformação - que caracteriza-se por ser uma "informação comprovadamente falsa ou enganadora que é criada, apresentada e divulgada para obter vantagens econômicas ou para enganar 
deliberadamente o público, e que é suscetível de causar um prejuízo público". (COMISSÃO EUROPEIA, 2018).

A publicação escolhida apresenta uma peça publicitária, uma legenda, um link e três Hashtags que geraram até o momento $^{2} 54$ comentários, 69 reações e 24 compartilhamentos. Abaixo, a publicação em questão:

Imagem 1: Publicação na fanpage do TSE, do dia 31 de outubro de 2018.

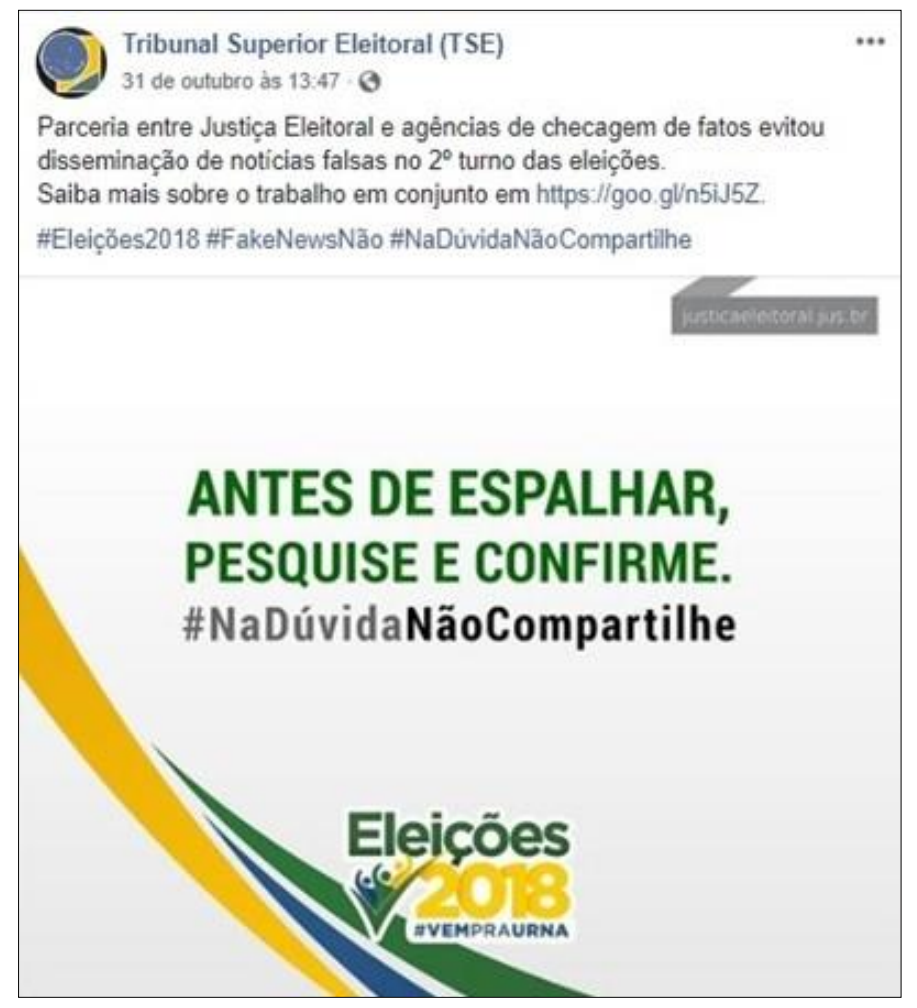

Fonte: https://www.facebook.com/TSEJus/, 2018.

\section{Metodologia}

A abordagem metodológica é a Análise do Discurso Mediada pelo Computador (ADMC) defendida por Susan Herring (2004) ao tratar sobre os discursos no meio on-line, de modo a analisar como as produções discursivas acontecem no ambiente virtual, pois segundo Susan Herring (2004), os métodos usados pela ADMC estão relacionados com a linguagem, comunicação e retórica, de modo a englobar tanto análises quantitativas quanto análises qualitativas dos dados coletados. Raquel Recuero (2013) aponta que 


\begin{abstract}
A ADMC funciona através de um estudo em níveis de análise, a saber: a estrutura, o sentido, a organização da interação e o comportamento social. É preciso, assim, mapear esses quatro pontos do fenômeno linguístico, focandose desde o nível micro até o nível macro do contexto da interação. (RECUERO, 2013, p. 243)
\end{abstract}

Os quatro níveis de análise apresentam características que permitem a codificação e a interpretação cuidadosa do objeto pesquisado. Com o nível Estrutura, analisa-se o objeto com base em seu texto verbal e corpus linguísticos; o nível Sentido, permite realizar uma análise semântica do objeto; o nível Interação mostra a interatividade dos usuários com a postagem em questão; e o nível Comportamento Social, a dinâmica social, as práticas sociais, suas influências e os conflitos gerados discursivamente.

Neste trabalho, para uma análise mais global do objeto, fez-se a junção dos níveis Interação e Comportamento Social num mesmo campo de análise, visto que as características desses dois níveis confluem entre si para a interpretação do objeto em questão quanto ao nível Interação e Comportamento Social.

É importante frisar que apesar dessa pesquisa analisar apenas uma publicação da página do TSE, ela nos apresenta profundas discussões a partir da análise ancorada nos 3 níveis de análise apontadas pela ADMC: Estrutura; Sentido; e, Interação e Comportamento Social. Assim, a partir dessa análise, a publicação escolhida trata sobre fake News logo após o resultado das eleições que sofreu casos de desinformação durante todo o seu processo eleitoral de 2018.

\title{
3 Facebook e as Eleições de 2018 no Brasil
}

O cenário político eleitoral brasileiro de 2018 apresentou aspectos diferenciados comparado às eleições anteriores, pois se tratou de um pleito ocorrido após casos confirmados de corrupção, aumento das manifestações sociais realizadas em diversas cidades do país, surgimento de novos partidos políticos e o impeachment de uma presidenta.

Além dessas ocorrências, o processo eleitoral no Brasil foi permeado pelo uso significativo dos sites de redes sociais tanto pelos candidatos ao realizarem suas campanhas eleitorais, quanto pelos órgãos públicos, com a finalidade de divulgar informações de utilidade pública aos eleitores. Os eleitores também tiveram uma grande 
participação quanto ao uso dos sites de redes sociais no compartilhamento e divulgação de seus posicionamentos políticos e partidários.

De acordo com Vieira (2013, p. 154), “estamos a todo instante executando nossas tarefas, mas também sendo acionados por outras informações, as quais entramos em contato a partir do momento que interagimos com as tecnologias". E Vargas \& Santos (2015), abordam que não é por acaso que se pode observar o sucesso das redes sociais, onde as relações virtuais, ainda que percebidas com uma menor importância do que as relações reais ou off line, vigoram durante grande parte do dia das pessoas.

E ainda, Pereira (2018) afirma que

\begin{abstract}
As aplicações de internet, que são o conjunto de funcionalidades que podem ser acessados por meio de um terminal conectado à internet, disponibilizam conteúdo. No entanto, na internet a lógica de distribuição do conteúdo se dá de forma diferente dos outros meios de comunicação, justamente por sua interatividade. Não são os meios de comunicação que enviam o conteúdo ao espectador que pode, passivamente, absorvê-lo ou não. $\mathrm{Na}$ internet o usuário busca pelo conteúdo, interage com o conteúdo e de certa forma o amplifica. (PEREIRA, 2018, p. 207).
\end{abstract}

A possibilidade de que essas relações possam gerar um impacto nas redes de relacionamento, garantem um incentivo, motivando o indivíduo a participar e a compartilhar conteúdo quase que ao mesmo tempo em que ele o experimenta. Assim, o compartilhamento de informações falsas e/ou publicadas fora do seu contexto factual também contribuíram para a formação de opinião sobre os candidatos políticos que disputaram a eleição no Brasil.

WhatsApp, Facebook, Twitter se tornaram redes sociais propulsoras de informações inverídicas, ocasionando uma complexa rede de notícias falsas sobre os presidenciáveis de 2018. A influência que as fakes news tiveram na eleição presidencial brasileira de 2018, no segundo turno, percorreu todo o período de campanha eleitoral obrigatório. Um processo de campanha que foi afetada, também, por mandados de retirada de notícias falsas determinados, inclusive, pelo TSE.

\footnotetext{
A divulgação de notícias falsas ou mentirosas é fenômeno conhecido internacionalmente como fake news e pode ser conceituado como a disseminação, por qualquer meio de comunicação, de notícias sabidamente falsas com o intuito de atrair a atenção para desinformar ou obter vantagem política ou econômica. (PEREIRA, 2018, p. 205).
}

Não só difundir inverdades, as fake news também interferem na formação de opinião pública dos eleitores em plena campanha eleitoral, pois seu conteúdo ao ser DOI: http://dx.doi.org/ 10.14393/par-v4n2-2019-50333 Paradoxos, Uberlândia, v. 4, n. 2, p. 71-87, jul./dez. 2019 |76 
massivamente disseminado colabora para que pessoas acreditem que aquela informação seja a verdade, principalmente quando uma empresa de comunicação conceituada e consolidada veicula esse tipo de conteúdo.

\begin{abstract}
A vantagem política, mais antiga e mais intuitiva, consiste na perda de prestígio do político opositor quando a ele se atribui fato ou característica infame. O proveito econômico advindo da difusão de fake news é fato mais recente e merece análise mais detida. (PEREIRA, 2018, p. 207).
\end{abstract}

Por isso, hoje ao se falar sobre fake News, não se pode limitar apenas a explicar sobre o que é uma notícia falsa, mas sim discutir sobre a extensão dela e seus efeitos na sociedade e, principalmente, como os discursos são reforçados à medida que vão sendo espalhados pelas redes sociais.

E quando tratamos sobre notícias falsas, podemos considerar também a expressão desinformação - que é uma prática “[...] determinada pelo viés da obtenção de vantagens econômicas ou políticas, de modo que, enganando o público, seja causado prejuízo aos processos políticos democráticos.” (SILVA, 2019)

Podemos destacar também as palavras de Claire Wardle ao comentar sobre uso da expressão fake news: "Estamos falando de um termo cunhado por Trump e usado por ele para atacar os jornalistas. É uma expressão paradoxal em si. Se é notícia, não pode ser falsa". (WARDLE, 2017)

D’Ancona (2018), ao tratar sobre a desinformação, ele menciona em suas pesquisas os aspectos da pós-verdade que englobam o crescimento e avanço de organizações que trabalham com o intuito de disseminar mentiras em prol de grupos de interesses, de modo que as notícias falsas são veiculadas para criar uma realidade ilusória sobre pessoas e/ou instituições.

Assim, temos o termo desinformação como uma expressão satisfatória ao tratarmos das informações falsas, pois ela "não se trata de uma simples ação, e sim de um complexo de ações que constroem um cenário intencionalmente determinado" (BRIZOLA; BEZERRA, 2018, p. 3319). Ou seja, a desinformação, portanto, corresponde a uma informação que está fora de seu contexto, sendo ela ainda fragmentada e manipulada, e que mostra uma realidade distorcida. 


\section{Análise do caso fanpage do TSE: discursos políticos reforçados}

A fanpage do TSE é a página oficial no Facebook do órgão máximo da justiça eleitoral do Brasil e que apresenta mais de 200 mil seguidores. Seu conteúdo apresenta imagens e textos de caráter informativo sobre os assuntos relacionados ao papel do TSE no país. Os administradores da página apresentam a seguinte descrição quanto ao uso da ferramenta:

Esta página foi criada com o objetivo de dar informações atualizadas e prestar serviços à população referentes ao sistema e processos eleitorais. Cumprindo sua missão de garantir a legitimidade do processo eleitoral e o livre exercício do direito de votar e ser votado, e a fim de fortalecer a democracia, o TSE utiliza esse espaço para informar e fomentar a cidadania e a participação popular. (TSEJus, 2018).

Por ser uma fanpage oficial e que apresenta uma quantidade considerável de seguidores optou-se por analisar a publicação do dia 31 de outubro de 2018, a qual possui sua relevância e foi selecionada por ter sido a primeira postagem publicada pelo TSE que trata sobre fake news logo após as eleições de 2018 que apresentaram escândalos e acusações envolvendo os presidenciáveis. Isso nos mostra a importância em discutir como os discursos são reforçados pelos usuários que interagem com a página, além de analisar como o conteúdo dela contribui para isso.

Como apontado na metodologia, a ADMC vai ser utilizada para realizar a análise do objeto que corresponderá a 3 níveis de análise: Estrutura; Sentido; e, Interação e Comportamento Social. E esses 3 níveis de análise podem ser encontrados na publicação selecionada, pois ela possui material verbo-visual que contempla uma análise completa que possa envolver aspectos quanto à estrutura, quanto ao sentido e quanto à interação e comportamento social. O critério de escolha da referida postagem, juntamente com esses níveis de análise, se deu por ela ser a primeira postagem do TSE pós-eleição que trata sobre fake news.

\subsection{Estrutura}

O primeiro nível de análise engloba os aspectos estruturais do objeto, incluindo textos, dados quantitativos e imagem. Quanto aos textos, a publicação possui legenda, hashtags, link 
e uma imagem verbo-visual que se harmonizam entre si, tendo como foco principal o cuidado que as pessoas devem ter ao disseminar informações falsas nas redes sociais.

$\mathrm{O}$ apelo acontece em consequência dos casos confirmados de fake news nas eleições de 2018 e uma forma do TSE dar uma resposta à população quanto ao seu trabalho de combate às notícias falsas e transparecer, também, que ele pode garantir a lisura do processo eleitoral brasileiro - uma de suas responsabilidades como órgão máximo da justiça eleitoral.

Ao publicar a legenda "Parceria entre Justiça Eleitoral e agências de checagem de fatos evitou disseminação de notícias falsas no $2^{\circ}$ turno das eleições. Saiba mais sobre o trabalho em conjunto em https://goo.gl/n5iJ5Z", chama atenção o fato de o TSE declarar que conseguiu impedir a disseminação de fake news no segundo turno.

Porém, ao clicar no link disponibilizado no final da legenda tem-se uma informação mais completa dos resultados desse trabalho conjunto, pois ao clicar no link, o usuário é direcionado para uma matéria divulgada no dia 29 de outubro de 2018 onde apresenta o seguinte lide: "Uma parceria inédita do Tribunal Superior Eleitoral (TSE) com agências de checagem de fatos (fact-cheking) evitou a disseminação de um conjunto expressivo de notícias falsas no último fim semana, véspera e dia da realização do segundo turno das eleições.".

Ou seja, o trabalho conjunto entre as agências de checagem e o TSE só trouxe resultados concretos quanto ao controle das fake news apenas na véspera do segundo turno, não controlando, portanto, os discursos reforçados e materializados que foram espalhados em muitos sites de redes sociais durante todo o primeiro turno e a maior parte do segundo turno. Vê-se com isso que o serviço de combate às fake news por parte do TSE foi tardio. Mas seu discurso possui outra intencionalidade, demonstrando que atitudes foram tomadas antes da finalização do pleito.

Ainda no âmbito textual, vê-se também o uso das hashtags \#Eleições2018, \#FakeNewsNão e \#NaDúvidaNãoCompartilhe que colaboraram para o impulsionamento de conexões na rede social, afinal, "as hashtags se transformaram em importantes conexões entre os usuários e seus discursos” (SENS \& PALAZZO, 2016, p. 4). Elas possibilitaram o reforço desse conteúdo publicado ao ligarem o termo "eleições de 2018" com o termo "Fake News", alinhando esta mesma ideia ao fato de os usuários investigarem a veracidade da notícia antes de compartilhá-la. 
Após a legenda e as hashtags utilizadas para reforçar um discurso contra as notícias falsas, a postagem apresenta ainda um banner que possui o texto: "Antes de espalhar, pesquise e confirme. \#NaDúvidaNãoCompartilhe”. E Mais abaixo, "Eleições 2018 \#VEMPRAURNA".

A expressão propõe novamente ao usuário pesquisar e confirmar sobre a veracidade de uma notícia antes de espalhá-la. Há também o uso novamente da hashtag \#NaDúvidaNãoCompartilhe, acrescido da hashtag \#VEMPRAURNA, trazendo novamente o reforço do discurso da postagem, aliado a um emissor TSE que, oficialmente, possui legitimidade no país.

A imagem tem as cores verde, amarela e azul em destaque, com fundo claro. Cores dos símbolos nacionais. Os tamanhos das fontes são variados, sendo o maior usado na frase principal "Antes de espalhar, pesquise e confirme". A hashtags \#NaDúvidaNãoCompartilhe com o mesmo tamanho e fonte, porém, com cores diferenciadas, dando destaque maior para expressão "NãoCompartilhe".

O endereço "justicaeleitoral.jus.br" ficou mais discreto, direcionando, primeiramente, o olhar do usuário mais para as partes inferior e central do banner, pois foram as palavras que se apresentaram com cores mais fortes e tamanho de fontes maiores.

Além disso, as informações que são possíveis destacar quanto à estrutura do objeto são os dados numéricos fornecidas pelo próprio Facebook. Dentre eles estão: 69 reações, incluindo 57 Curtir e 12 Haha (risos); 54 comentários; e 24 compartilhamentos. A publicação em questão teve como critério de escolha por ser a primeira postagem publicada pelo TSE sobre fake news logo após as eleições de 2018, com a possibilidade de verificar a repercussão gerada com o resultado de um das eleições que mais envolveram escândalos e acusações de desinformações sobre os presidenciáveis de 2018.

\subsection{Sentido}

A postagem sugere muitos sentidos que reforçam discursos políticos, um deles se refere à hashtag \#VEMPRAURNA que ao ser mencionada na postagem, direciona o usuário, mesmo que subliminarmente, à memória da hashtag \#VemPraRua que foi utilizada para chamar os brasileiros a irem paras as ruas e se manifestarem contra o aumento da passagem de ônibus em 2013, e em 2015 contra o governo petista. 
A associação das duas hashtags, mesmo que involuntariamente por parte do TSE, mostra que a mídia colabora para a produção e materialização de práticas discursivas vindos de espaços sociais e políticos diferentes, mas que possuem o poder (re) contar histórias (GREGOLIN, 2007).

O \#VemPraRua apareceu, em 2013, no cartaz convocatório do Movimento Passe Livre (MPL) de São Paulo, em sua página no Facebook, que dizia: "Vem pra rua vem, contra o aumento!". Naquele momento, o MPL marcava um Ato contra o aumento das passagens de ônibus, do Metrô e da CPTM, para o dia 06 de junho. (MALINI et al. 2014, p. 6).

Porém, antes da hashtag se tornar um apelo para a realização de manifestações sociais nas ruas contra o aumento das passagens de ônibus, o filme publicitário da empresa Fiat, veiculado no primeiro semestre de 2013, convida os brasileiros a irem para as ruas usando o slogan "Vem pra rua, que a rua é a maior arquibancada do Brasil".

A campanha da Fiat tinha como temática principal a Copa das Confederações, e era uma espécie de convite, com música e letra criada pelo grupo O Rappa, exclusivamente para o filme, que dizia a todo instante: "Vem pra rua, que a rua é a maior arquibancada do Brasil". A campanha acabou se tornando hino das passeatas e mobilizações ao redor do país. (MADAJI, 2014, p. 113).

Mas o uso dessa hashtag e o discurso "Vem pra rua" foi além. No ano de 2015 a \#VemPraRua começou a ser novamente utilizada para incitar novos protestos, mas agora seriam contra o governo da então presidenta Dilma Rousseff e contra o Partido dos Trabalhadores (PT). Mostrando que mais uma vez, as redes sociais serviram como ferramenta para materializar discursos e suas reproduções.

Assim, consolidou-se um discurso de ódio contra o PT já massificado pela mídia e a reverberação das manifestações geradas pela convocação midiática de todos irem para as ruas. Percebe-se, com isso, que o uso da hashtag \#VemPraUrna agrega valores sociais e políticos em sua história discursiva, legitimando assim um discurso político já instaurado pela mídia e pela sociedade.

Criticamente, vê-se um órgão público que utilizou durante todo o período eleitoral uma hashtag que poderia acionar na memória dos eleitores um posicionamento político que desfavorecesse um dos partidos em disputa. Porém, ao mesmo tempo, é possível perceber também uma chamada para que os eleitores se manifestassem nas urnas, por meio de seus votos. 


\subsection{Interação e ao Comportamento Social}

Os usuários da fanpage do TSE que apresentaram interação entre si e com o conteúdo da postagem em análise reforçou discursos políticos que hora favoreciam e hora discordavam das informações publicadas na postagem e nos comentários. Os recursos de interação como curtir, comentar e compartilhar disponibilizados pelo Facebook serviram para reforça e legitimar os discursos do próprio TSE e dos usuários que se manifestaram na página. Abaixo apresentam-se exemplos dessas interações.

Imagem 2: Comentário na fanpage do TSE da publicação do dia 31 de outubro de 2018.

\section{Esperando o TSE agir contra o candidato Bolsonaro que,} mesmo depois de advertido, continuou usando a fake news do kit gay e se elegeu com base nela e muitas outras

\section{Curtir - Responder - 2 sem}

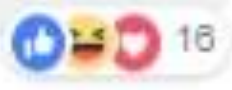

Fonte: https://www.facebook.com/TSEJus/, 2018.

A imagem acima se refere ao comentário mais recente publicado na postagem analisada. Com 16 reações entre Curtir, Haha e Amei, o comentário rendeu outras mensagens de discordância e de apoio. Seu texto apresenta uma insatisfação quanto ao trabalho do TSE no combate das fake news, além de utilizar o espaço para mostrar seu desagrado à vitória do candidato eleito Jair Bolsonaro. O comentário mostra ainda a informação sobre a fake news do Kit Gay disseminada pelos apoiadores de Jair Bolsonaro e defendido pelo próprio candidato. Uma das respostas de oposição a esse comentário pode ser conferida abaixo.

Imagem 3: Comentário na fanpage do TSE da publicação do dia 31 de outubro de 2018.

Tudo o que é contra o pt é fake se enxerga vocè é um completo alienado, você acha que um candidato à presidência iria no $\mathrm{JN}$ com um livro que nunca existiu ?passar o maior fiasco de sua vida ao vivo para o mundo inteiro ver? Deixa de ser tonto aliás militonto pare de passar vergonha!

\section{Curtir-Responder - 2 sem}

Fonte: https://www.facebook.com/TSEJus/, 2018. 
O comentário da imagem 3 apresenta discordância e afirma que o Kit Gay não é uma fake news. Esse usuário tenta legitimar sua fala ao dizer que o candidato foi ao Jornal Nacional "JN" para apresentar em rede nacional "para o mundo inteiro ver" o livro que faria parte de um Kit Gay produzido e distribuído no governo petista.

Seu comentário também traz um reforço ao discurso de oposição ao mencionar palavras como "alienado" e "militonto", juntamente com o apelo "pare de passar vergonha", denotando com isso que o Kit Gay não é uma notícia falsa e os que defendem o PT possuem pensamentos que devem ser desconsiderados por serem alienantes e "tontos".

Isso mostra que as práticas discursivas estão inseridas em relações de poder que legitimam discursos e os tornam como verdade. Para Foucault (1996), a produção do discurso é ao mesmo tempo controlada, selecionada, organizada e redistribuída por certo número de procedimentos de controle, materializando discursos (re)construídos na sociedade pelas relações de poder, tomando os discursos como verdades e estas, por sua vez, criam novos discursos para garantir a continuidade desse poder.

Este comentário (imagem 3) não contabilizou nenhuma reação durante a pesquisa, diferentemente do mostrado na imagem 2 que apresentou 16 reações, sendo 7 Curtidas, 6 Haha e 3 Amei, mostrando com isso que o apoio de outros usuários foi mais favorável ao comentário da imagem 2 do que ao da imagem 3. A legitimação de um discurso que desfavorece o TSE e o candidato eleito Jair Bolsonaro ficou também evidente em outros comentários.

Imagem 4: Comentário na fanpage do TSE da publicação do dia 31 de outubro de 2018.

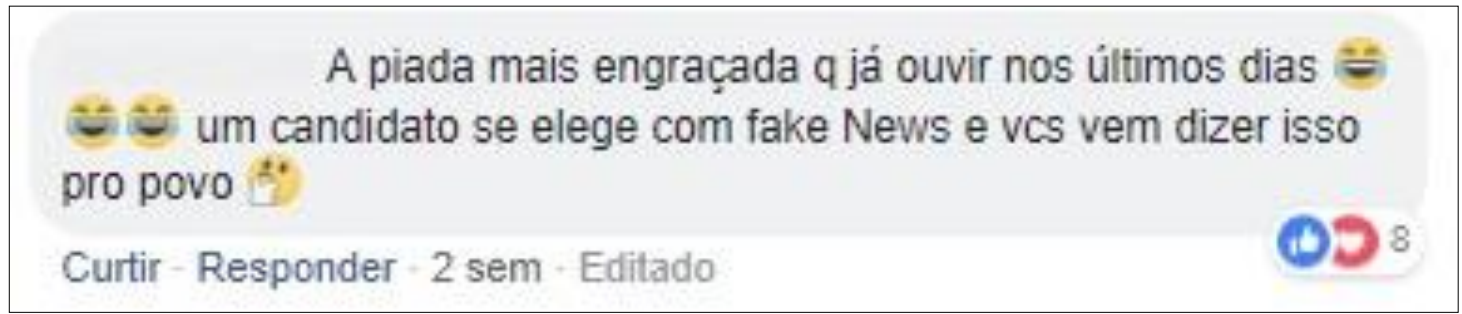

Fonte: https://www.facebook.com/TSEJus/, 2018.

Além de não demonstrar apoio ao candidato eleito, o usuário se utiliza de sarcasmo e de emojis que desmerecem o TSE e sua postagem. O usuário acredita que o referido candidato se elegeu disseminando fake news, enquanto o TSE tenta convencer que evitou a proliferação das notícias falsas. Defende ainda, a sua descrença ao TSE e 
direciona o seu pensamento à sociedade com a expressão "vem dizer isso pro povo". Seu discurso convoca, mesmo que implicitamente, o povo a não acreditar no órgão que possivelmente tenta enganar a sociedade. Vê-se que esse discurso ganha reforço de outros usuários que clicaram 6 vezes em "Curti” e 2 vezes em "Amei”.

Imagem 5: Comentário na fanpage do TSE da publicação do dia 31 de outubro de 2018.

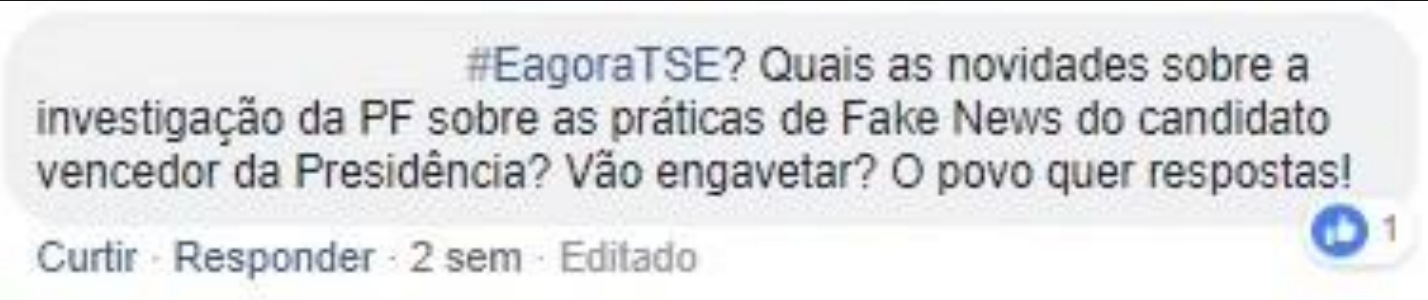

Fonte: https://www.facebook.com/TSEJus/, 2018.

A imagem 5 é um pedido, particular e ao mesmo tempo coletivo, de respostas sobre as investigações da Polícia Federal $(\mathrm{PF})$ quanto às práticas de disseminação de notícias falsas que, possivelmente, o candidato eleito realizou. Ao utilizar a hashtag \#EagoraTSE? o usuário indaga diretamente o órgão sobre a situação de notícias inverídicas espalhadas e que não somente ele, mas toda a população "o povo quer respostas" exige um retorno do TSE.

Ainda analisando o nível de Interação e Comportamento Social, dos 54 comentários, a publicação apresentou apenas 1 comentário de apoio ao TSE, mas que não deixou de expressar sua insatisfação quanto o resultado das eleições 2018, conforme expõe a imagem abaixo:

Imagem 6: Comentário na fanpage do TSE da publicação do dia 31 de outubro de 2018.

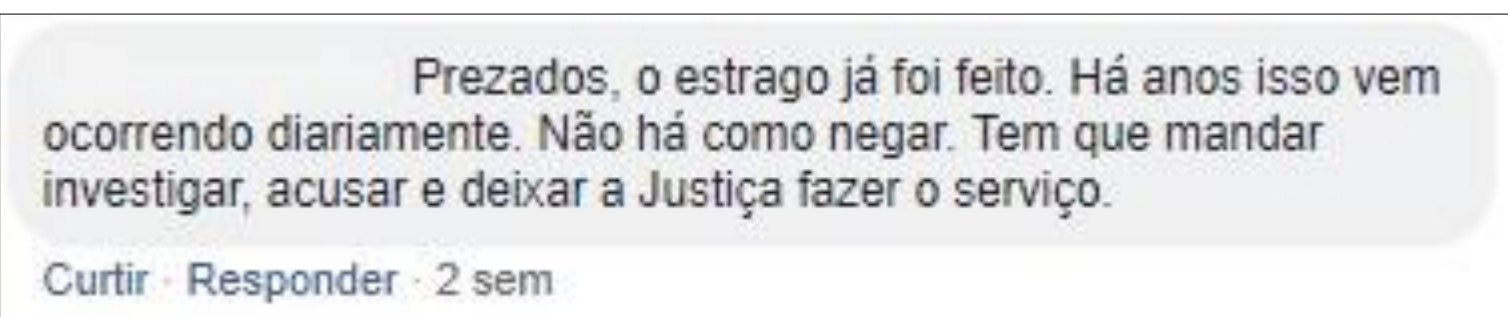

Fonte: https://www.facebook.com/TSEJus/, 2018. 
Imagem 7: Comentário na fanpage do TSE da publicação do dia 31 de outubro de 2018.

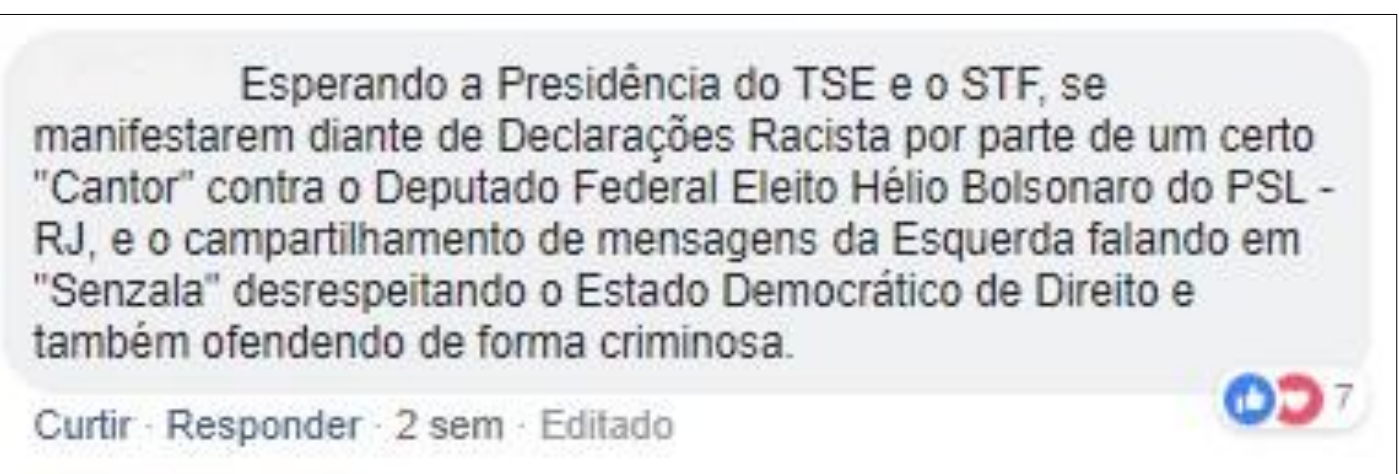

Fonte: https://www.facebook.com/TSEJus/, 2018.

Já o usuário da imagem 7 apresenta um discurso positivo ao Partido Social Liberal (PSL). Sua declaração na rede social do TSE apresentou um discurso que, também, ganhou reforço e legitimidade de outros usuários, somando com isso 7 reações positivas, entre Curtir e Amei.

\section{Considerações finais}

O presente artigo apresentou uma análise da postagem fanpage do TSE, publicada no dia 31 de outubro de 2018, que fala sobre o cuidado de compartilhar notícias falsas nos sites de redes sociais. A postagem se refere à preocupação por parte do TSE em tentar evitar que mais fake news fossem espalhadas no último final de semana das eleições de 2018 no Brasil.

A análise foi realizada com base nos 3 níveis apontados pela ADMC, são eles: Estrutura, Sentido e Interação e comportamento social. Em cada um deles foram apresentados exemplos, discussões e reflexões de como o conteúdo informativo da página oficial do TSE pode reforçar e materializar discursos políticos que referenciaram as eleições de 2018 no país.

Portanto, os resultados da análise mostraram que as práticas discursivas que se materializam nos sites de redes sociais, neste caso no Facebook, estabelecem relações de poder que reforçam discursos e os tornam como verdades. Assim, os recursos de postar, curtir, comentar e compartilhar disponibilizados pelo Facebook são aspectos que podem contribuir para reproduzir discursos e dar continuidade de poder, baseados em regimes de verdade - seja ela fake ou não. 


\section{Referências Bibliográficas}

BRIZOLA, Anna Brisola; BEZERRA, Arthur Coelho. Desinformação e circulação de "fake news": distinções, diagnóstico e reação. Apresentado no GT-5 - Política e Economia da Informação do XIX Encontro Nacional de Pesquisa em Ciência Da Informação - ENANCIB, 22 a 26 de outubro de 2018 - Londrina - PR. Disponível em: http://enancib.marilia.unesp.br/index.php/XIXENANCIB/xixenancib/paper/viewFile/12 19/1636. Acessado em: 17/09/2019. https://doi.org/10.22478/ufpb.1809$\underline{4775.2017 \mathrm{v} 13 \mathrm{n} 1.34953}$

COMISSÃO EUROPEIA. Comunicação da comissão ao parlamento europeu, ao conselho, ao comitê econômico e social europeu e ao comitê das regiões: combater a desinformação em linha: uma estratégia europeia. Bruxelas, 2018. Disponível em: https://eur-lex.europa.eu/legal-content/PT/TXT/?uri=CELEX\%3A52018DC0236.

Acesso em: 17/setembro/2019. https://doi.org/10.14195/978-989-26-1634-6_7

D'ANCONA, Matthew. Pós-verdade: a nova guerra contra os fatos em tempos de fake news. Barueri/SP: Faro Editorial, 2018. https://doi.org/10.20396/etd.v21i1.8652833

FOUCAULT, Michel. A Ordem do Discurso. São Paulo: Edições Loyola, 1996.

GREGOLIN, Maria do Rosário. Análise do Discurso e mídia: a reprodução das identidades. Revista Comunicação, Mídia e Consumo, São Paulo, Vol. 4, No11, 2007, p. 11-25. Disponível em: http://www.revistas.univerciencia.org/index.php/comunicacaomidiaeconsumo/article/v iewFile/6865/6201. Acesso em abril de 2014. https://doi.org/10.22297/dl.v7i1.2982

HERRING, S. C. Computer-Mediated Discourse Analysis: An Aproach to Researching Online Behavior. Em: S. A. Barab, R, Kling, and J.H. Gray (Eds), Designing for Virtual Communities in the Service of Learning. New York: Cambridge University Press, 2004. https://doi.org/10.1017/cbo9780511805080.016

MALINI, Fábio; GOVEIA, Fábio; CIARELLI, Patrick; CARREIRA, Lia; HERKENHOFF, Gabriel; REGATTIERI, Lorena; LEITE, Marcus Vinicius. \#VemPraRua: Narrativas da Revolta brasileira. ALAIC, 2014. Disponível em: http://congreso.pucp.edu.pe/alaic2014/wpcontent/uploads/2013/12/GI1-Malini-GoveiaCiarelli-Carrerira-Herkenhoff-RegattieriVinicius.pdf. Acessado em: 20/11/2018.

MANDAJI, Carolina Fernandes da Silva. O gigante adormecido vem pra rua: construções enunciativas de Johnnie Walker e Fiat durante as manifestações brasileiras de 2013. Revista CMC - Comunicação, Mídia e Consumo. Ano 11, vol.11 n.30 p.107-121 jan./abr. 2014. Disponível em: http://revistacmc.espm.br/index.php/revistacmc/article/view/679/pdf. Acessado: 20/11/2018. 
PEREIRA, Rodolfo Viana (Org.). Direitos políticos, liberdade de expressão e discurso de ódio. Volume I. Belo Horizonte: IDDE, 2018. https://doi.org/10.32445/97885671340621

RECUERO, R; SOARES, P. Violência simbólica e redes sociais no facebook: o caso da fanpage "Diva Depressão". Galáxia (São Paulo, Online), n. 26, p. 239-254, dez. 2013. Disponível em: http://www.scielo.br/pdf/gal/v13n26/v13n26a19.pdf. Acessado em 20/11/2018. https://doi.org/10.1590/s1982-25532013000300019

SENS, André Luiz; PALAZZO, Luiz Antônio Moro. As hashtags como expressão da cultura transmidiática. II Jornada Internacional Geminis. Universidade Federal de São Carlos, 2016. Disponível em: https://www.researchgate.net/publication/322723653_As_hashtags_como_expressao_da _cultura_transmidiatica. Acessado_ em 20/11/2018. https://doi.org/10.17771/pucrio.acad.8755

SILVA, Fernanda de Barros da. O regime de verdade das redes sociais on-line: pósverdade e desinformação nas eleições presidenciais de 2018. Dissertação de Mestrado defendido no Programa de Pós-Graduação em Ciência da Informação, convênio entre o Instituto Brasileiro de Informação em Ciência e Tecnologia e a Universidade Federal do Rio de Janeiro/Escola de Comunicação, 2019. Disponível em: http://repositorio.ibict.br/bitstream/123456789/1027/1/Fernanda\%20de\%20Barros\%20d a\%20Silva_Mestrado_2019.pdf. Acessado em: 17/09/2019. https://doi.org/10.1590/1981-5344/2416

VARGAS, Arthur Maia; SANTOS, Regina Celia Xavier dos. Interações sociais no Facebook: um estudo sobre a construção dos processos de capital social. Universitas: Arquitetura e Comunicação Social, v. 12, n. 1, p. 17-24, jan./jun. 2015. Disponível em: https://www.publicacoesacademicas.uniceub.br/arqcom/article/download/3335/2714.

Acessado em: 20/11/2018. https://doi.org/10.5102/uc.v12i1.3335

VIEIRA, Manuela do Corral. Os jovens flâneurs.com: a construção e a liquidez da identidade no espaço das redes sociais da internet. Tese de doutorado defendida no Programa de Pós-Graduação em Antropologia da Universidade Federal do Pará. 2013. https://doi.org/10.31419/issn.2594-942x.v62019i3a6jvtca

Data Recebimento: 29/08/2019

Data Aprovação: 11/2019

\footnotetext{
${ }^{1}$ Este trabalho foi apresentado na Divisão Temática 8 - Estudos Interdisciplinares do XXI Congresso de Ciências da Comunicação na Região Nordeste, realizado de 30 de maio a 1 de junho de 2019, na Universidade Federal do Maranhão (UFMA).

2 Dados coletados no dia 20 de novembro de 2018, retidos da página https://www.facebook.com/TSEJus/.

${ }^{3}$ A autora apresentou esta fala no Festival 3i, realizado no Rio de Janeiro em novembro de 2017. Disponível em: https://piaui.folha.uol.com.br/lupa/2017/12/23/fake-news-dizer-ou-nao-dizer/. Acessado em: 17/09/2019.
} 